\title{
Exploring The Mechanisms Of Distraction From In-Vehicle Technology: The Development of the PARRC Model.
}

\author{
Katie J. Parnell, Neville A. Stanton \& Katherine L. Plant
}

\section{Introduction}

On a clear Sunday morning in September 2012, Victoria McClure was driving on the A4 near Reading, England, when she hit a cyclist, killing him on impact. In a subsequent court investigation it was discovered that 500 meters prior to the site of the incident the road was straight which, given the clear visibility of the day, should have allowed Victoria McClure to see the cyclist for approximately 18 seconds before she hit him if driving at the limit of $60 \mathrm{mph}$, longer if she was driving slower. The court discovered that prior to the incident she had been interacting with her in-vehicle satellite navigation system, which the court ruled caused her to 'drive blind' for the duration of the 18 seconds. The lack of skid marks on the road evidence that she failed to spot the cyclist, even at the last minute and perform an emergency brake. The defence argued the cyclist was wearing low visibility clothing that prevented him from being seen but the court convicted Victoria McClure of 'dangerous driving' with 18 months imprisonment (BBC News, 2013). This is an extreme example of the many incidents that occur due to distraction from in-vehicle technology, and it is the focus of much research to actively seek ways to mitigate such events (e.g. Lee et al, 2004; Donmez et al, 2008). One focus within this is to realise the utility of in-vehicle technology while managing the adverse impacts it can have on safety (Lee, 2014; Jamson et al, 2004).

Advances in technology have facilitated a competitive relationship between manufacturers of wireless devices, computers, and automobiles that has helped to propel the implementation of advanced devices such as Intelligent Transport Systems (ITS), e-mail servers and eco-driving systems, into vehicles (Ranney et al, 2000). This satisfies the needs of drivers who are becoming more reliant on the conveniences that wireless technology offer (Dingus et al, 2006). Emphasis by manufacturers on reducing time-to-market has led system developers to implement new technological developments at a rapid pace, without full testing (Leveson, 2011). Hence, developments may align with perceived consumer needs rather than their capabilities and limitations. Legislation on the use of devices and inbuilt technology in vehicles often has to play catch-up, advising on usability after their widespread use, as is the case of handheld mobile phones (e.g. Redelmeier \& Tibshirani, 1997). Indeed, Harvey and Stanton (2013) identified task times for operating different in-vehicle devices and showed that entering a destination into the satnav took longer, on average, then the 15-second maximum recommended interaction time (Green, 1999; Society of Automative Engineers, 2002). Contending that 
the task completed by Victoria McClure should never have been approved for use in the vehicle in the first place. This supports Leveson's (2011) claim that increasingly complex technology is developing faster then techniques employed to respond to their potential safety issues; leaving users exposed to risk. As increasing levels of death by dangerous driving convictions align with the increased engagement with technology in vehicles (Office for National Statistics, 2013; RAC Report on Motoring, 2013), the safety issues needed to be realised.

The main goal of the driver is, ultimately, to reach the destination safely (Cnossen et al, 2004), with behaviour regulated to achieve this goal (Groeger, 2000). Technology has expanded the potential goals available to drivers, e.g. making a phone call to the person they are due to meet or driving in an eco efficient manner in response to eco-displays (Dogan et al, 2011). The adverse effects of telecommunication devices (McCartt et al, 2006), music systems (Mitsopoulos-Rubens et al, 2011), and email systems (Jamson et al, 2004) on driving performance is well documented. However, increasingly drivers are provided with systems that aim to assist the driver with the driving task for example, ITS, navigation systems and efficiency information systems. Yet, although these technologies aim to enhance and improve the driver's performance they have also been shown to have adverse effects on their safety, as they engage the driver's eyes, mind and hands away from the road and therefore the main driving goal (Harms \& Pattern, 2003; Jensen et al, 2010; Kircher et al, 2014). Thus, a fine line exists between devices that assist the driving goal of arriving safely and devices that detract from it. With increasing levels of dangerous driving convictions, this line needs to be clearer to drivers (Cnossen et al, 2004; Dogan et al, 2011).

\subsection{Driver Distraction from in-vehicle technology: Definition and Theory}

In order to manage the issue, the mechanisms through which distraction occurs need to be recognised and modelled (Young \& Salmon, 2012). The study of driver distraction can be dated back over 50 years (Brown et al, 1969). Yet, the complexities of distraction, it's multiple sources and contexts of occurrence, mean that currently no universal definition or model has been achieved (Young et al, 2007; Regan et al, 2009). Several models have been influential however, such as Sheridan's (2004) Control Theory Perspective model which applied control loops to the issue of driver distraction to identify novel aspects of the phenomena. Lee, Regan and Young's (2008) Breakdown in the Multilevel Control Model has also been highly influential and aligns with their definition of driver distraction which has achieved some consensus in the field (e.g. Liang \& Lee, 2010; Young \& Lenne, 2010; Hosking, Young $\&$ Regan, 2009). They define driver distraction as the: "diversion of attention away from activities 
critical for safe driving towards a competing activity" (Lee et al, 2008:38) (e.g. Liang \& Lee, 2010; Young \& Lenne, 2010; Hosking, Young \& Regan, 2009), although it is not without critique (Regan et al, 2011). It's relevance to distraction from in-vehicle technologies is highlighted here, not only because it captures how technology is encouraging more activities into the vehicle (Walker et al, 2015) but also by giving importance to the safety critical impact of engaging with different in-vehicle devices.

Contemporary approaches to driver distraction have uncovered that distraction is not an error in itself but that errors occur as result of distraction (Stanton \& Salmon, 2009), yet the mechanisms through which distraction impacts errors and the wider systemic influences are not known (Young \& Salmon, 2012). Over time theories of distraction have switched from considering it a passive phenomenon that the driver is subjected to, towards a more active process of which the driver has control over (Cnossen et al, 2000). Early work simply suggested that distraction is the result of inattention, i.e. a failure to look at the critical aspects of the roadway due to reduced awareness (Dingus, 2006). Evidence to support this applied Wickens (2002) Multiple Resource Theory to driver distraction, suggesting that the attentional resources that tasks demand are finite which limits the ability to engage in more then one task sharing the same resources at any one time. Furthermore, Wierwille (1993) highlighted the importance of the visual resource in driving and the need for in-vehicle technologies to utilise other resources such as auditory channels that are less important to the driving task.

Alternative theories that suggest that drivers play a more active role in distraction imply that drivers' structure their performance by adapting their behaviour to be consistent with the demands of the task, predominantly by slowing down to increase headway and time to collision (Noy, 1989; Hockey, 1997; Cnossen et al, 2000;). Research showing drivers slowing down when on the phone (Rakauskas, et al., 2004) or using navigation aids (Cnossen et al, 2000) supports this. Hockey's (1997) compensatory control theory states that under high demands drivers adapt their behaviour to prioritise their main task, driving, leaving lesser important goals to decline in order to maintain safety. However, there are mixed findings in the field and incidents such as Victoria McClure's suggests drivers do not always prioritise the driving task. It could be proposed that in-vehicle tasks relating to the driving task e.g. navigation aids and ITS, are wrongly prioritised as they are perceived by drivers to enhance the main driving goal (Cnossen, 2000), when in reality that are just further distractions. Furthermore, where drivers have a heightened perception of their capabilities while driving they are likely to wrongly believe they can undertake demanding secondary tasks safely (Horrey et al, 2008). Fuller (2000) suggests under some circumstances drivers may be motivated to take on highly demanding tasks that exceed their capability, 
even though they are aware of the enhanced risk of collision. The perceived value outweighing the potential risk. Indeed many people admit to using mobile phones and other devices while driving despite knowing the associated risks (McCartt et al, 2006; Lerner et al 2008).

Cnossen et al (2000) highlights the important differences between approaches that focus on inattention as the cause of distraction and those that focus on the mechanisms drivers use to incorporate the primary and secondary driving task together. Inattention suggests secondary tasks will invariably result in failure to attend to the driving task, having undesirable effects on performance. Whereas theories that suggest a strategic application of attention while driving with a secondary task imply the driver has a more active role, restructuring their performance to manage increased demand (Cnossen et al, 2000). Yet it is unclear what trade-offs drivers make when they decide to engage with technology behind the wheel, what information they are utilising when making their decisions, or the mechanisms through which distraction occurs. It is evident a more cohesive model is required to better understand the issue and present the mechanisms of distraction such that behaviour may be better predicted and effective countermeasures developed. Model development is advantageous to ergonomic research as models enable predictions of behaviour to be made, as well as being a useful means of presenting and advancing research (Moray, 1999).

\subsection{Driver distraction from in-vehicle technology: Approach and countermeasures}

The approach to mitigating driver distraction has been inline with theories that place the driver as responsible for their attentional strategy while driving and these have remained relatively unchanged over time (Regan et al, 2011; Young \& Salmon, 2015). To date, interventions into driver distraction have focused on regulating the drivers' behaviour with mitigation strategies aimed at educating drivers, and legislation that places the blame solely on the individual (Tingvall et al, 2009). Such is true of Victoria McClure's case, yet this current approach is not considered proactive by some (e.g. Leveson, 2004; Dekker, 2011; Leveson, 2011; Young \& Salmon 2015). Young and Salmon (2015) highlighted the issues currently found by drivers who must ignore the technology put into vehicles by manufacturers that is then later outlawed by the government. Indeed, there has been a surmountable body of research citing 'willingness to engage' as a key factor in incidents resulting from technology that is encouraged by manufacturers but that is not accounted for in legislation (Ranney et al, 2000; Lerner et al, 2008; Olsen et al, 2005; Dingus et al, 2006). 
Tingvall et al (2009) note that distraction cannot be eliminated entirely but to minimise it all stakeholders that hold responsibility over distraction need to be realised and united towards a common design strategy. This requires identifying higher-level factors that have a high influence in how distraction arises across the whole road transport system Young \& Salmon (2015). Rasmussen's (1997) risk management framework highlights 6 hierarchical levels that interact with one another to determine how a system functions as a whole. At the top-level government policies and legislation inform regulators such as the media, manufacturers, and road designers. In turn these influence individual companies, their policies and management which effect the behaviour and environment surrounding workers and their equipment residing at the bottom of the systems hierarchy. In the vehicle this bottom level relates to the driver and the tools they have available to them in the vehicle (Young \& Salmon, 2015). Integral to the system framework is that it is not just the individual elements that are important in maintaining a safe system, but the interactions between them (Cassano-Piche et al, 2009). Policy must propagate down the system to be regulated and adopted by the lower levels. Bottom-up feedback from the lower levels upwards is also important to maintain up to date policies on new technology developments (Rasmussen's, 1997). Applying Rasmussen's (1997) framework, Young \& Salmon (2015) identified an array of elements that influence distraction related incidents residing outside of the driver's control, highlighting the limitations of a driver-centric approach. For novel and influential countermeasures, strategies are required that account for the wider driving system and the interactions between elements within it (Salmon et al, 2012). Yet, no theory or model of distraction from in-vehicle technology has been able to incorporate systems thinking.

\subsection{Aims and Objectives}

This paper aims to explore the underlying mechanisms of distraction from in-vehicle technology to uncover the factors involved in distraction and how they may relate to an explorative model that incorporates a wider systems view of the phenomena. It is then hoped that this will enable the responsibility that needs to be taken by these systems factors to be identified for implementation in future countermeasures.

\section{Method}

This paper proposes a novel method of studying the issue by applying a grounded theory approach to the informative yet diverse literature on driver distraction and in-vehicle technology use in order to explore the key mechanisms of the phenomena from within the literature in which it is studied. 


\subsection{Grounded Theory}

Grounded Theory is not novel to the driving domain. It has been used to explore elderly drivers behaviour (Musselwhite \& Heddad, 2010), as well as their passengers and perceptions of in-vehicle technology (Vrkljan et al, 2007). Furthermore, Stanton and Salmon's (2009) factors of accident causation were founded within the literature on human error in road transport. It is a method used to explore possible issues or phenomenon from within the literature it originates in order to gain insight into its underlying mechanisms and behaviours (Glaser \& Strauss, 1967). It does this by constantly comparing and reviewing data to seek out themes, factors and interconnections in an iterative manner. It is frequently used to develop theories and models without a priori expectations in order to gain a novel understanding of a phenomenon. The advantage of this is that it provides conclusions of high ecological validity from an abundant yet narrow depth of literature across an array of different sources (Glasser, 2001). Its qualitative nature means rich data sets are generated. However, the method is not without critique, it has been deemed to over simplify complex issues and interrelations, as well as constraining analysis such that theory is not guided by data but instead limited by it (Layder, 1998). Despite this, as a method from which to develop a model for further exploration of the current literature it, it offers the opportunity for novel insight that builds on current research (Cavaye, 1996). It is also credited for its supplementary use with other methodologies (Strauss \& Corbin, 1994).

The advantage of the approach in accounting for wider systems factors within ergonomic research is noted by Rafferty et al (2010) who applied grounded theory to the military domain to draw key causal factors involved in the safety performance of a system from the literature in which the phenomena was studied. Reflecting on qualitative accounts of the actual behaviour within the field Rafferty et al (2010) identified key system factors and the interrelations between them. They also exposed how these factors influenced system performance and the emergence of safety within the system. This enabled novel countermeasures that targeted elements contributing to system safety and mechanisms that led to adversity. It is hoped that applying the same approach to the road transport system will have similar virtues in understanding how driver distraction influences the emergence of safety from the interconnection of multiple systemic levels.

\subsection{Document analysis}

In order to expose the mechanisms of distraction from in-vehicle technology the literature from which the phenomena is cited was required. It is important that the search criteria for this literature yielded the array of research explicitly looking into distraction from technology. Hence a criterion for included 
literature was required. This required applying Lee et al's (2008) definition of driver distraction and the understanding that driving is a goal directed activity (Groeger, 2000) with safety as a primary goal and secondary tasks such as those associated with in-vehicle technology providing the driver with an increased array of goals, secondary to the primary driving goal.

A comprehensive review of the scientific literature encompassing English-language articles was undertaken using purposeful sampling to select items directly relating to the concepts under investigation. The 'Web of Science' database was used as a tool to locate relevant literature, conducting a combined search over multiple databases linked to the platform. An initial search using the terms 'automobile driving' and 'distraction' revealed 393 items, indicating the extent of the literature on driver distraction to date. Further criteria were required to determine technology based distractions in line with the definition.

Inclusion criteria: Peer-reviewed research articles were included incorporating journal articles, books and conference proceedings. The original search was filtered by key words. Filtering by 'technology' produced 49 items. Filtering by the term 'goal' revealed 21, however many of these related to an alternative use of the term by some authors as another word for 'aims' in relation to the research paper. The items revealed by these filters were reviewed in accordance with how they related to concepts under consideration i.e. it was essential that technological distraction events were found consistent with Lee et al's (2008) definition.

Exclusion criteria: Items that were not deemed relevant were excluded, these included papers that did not explicitly state a relation to distraction such as those focusing on substance use or fatigue. All papers that related to distraction from causes other than in-vehicle technology were excluded, for example from passengers, daydreaming, external stimuli or due to inexperience. Furthermore, items that were not thought to represent peer reviewed research such as policy articles and book summaries were also removed.

Papers meeting the criteria were used to find other relevant papers using cited references. The objectives, motivations, independent and dependant variables and findings of potential articles were reviewed to determine if they captured distraction from in-vehicle technology as determined by the underlying goals of the driver, the corresponding activities and their relation to safety. In total 33 citations relating to the management of activities, overarching goals and driver distraction from in- 
vehicle systems were identified as meeting the criteria. These ranged in publication date from 1986 to 2014, consistent with time period in-vehicle technology began to develop and became increasingly more common place.

While 33 may seem a relatively small number of studies to review for the development of a model it must be considered that utilising goal-based behaviour as a way of analysing distraction is a narrowly focused area. The aim of this research is to develop a model that is grounded in the literature to understand the current factors that may be implicating distraction from this perspective, as it is thought not to have been achieved previously. The limited literature points to potential gaps in the knowledge base, further motivating the potential to develop a model that can represent the concepts. Lansdown et al, (2015) identified similar issues when reviewing literature surrounding multiple driver distractions from a systems perspective, only finding 10 relevant papers. These papers explicitly looked for references to a systems perspective and multiple sources of attention that led to distraction. These differed to those items sought in this research that looked for the implications technology had on the goals of the driver and the underlying mechanisms leading to distraction consistent with the set definition. This research did not require papers that referred to a systems perspective, rather items were utilised to inform on a systems perspective.

\section{Results and Discussion}

Qualitatively analysis of the literature using open coding identified a total of 25 factors as contributors of distraction (see Appendix A for a table showing all 33 papers and the factors identified within them). The majority of articles had more than one of these factors, indicating potential interactions. Factors were ordered by their presence in the literature in descending order and a scree plot highlighted that the top 5 factors held the largest contribution to the discussion in the literature (figure 1). These factors were: adapt to demands, goal conflict, behavioural regulation, goal prioritisation and resource constraints. Similar comments of circular reasoning can be made as those aimed at Rafferty et al (2010), stating that characteristics may be cited in one instance and then repeatedly analysed in the literature, but it does offer a way of reducing complexity and focusing on a core set of factors as an initial foray. As 25 factors were identified in total it's evident a large number of factors are discussed widely in the literature. 


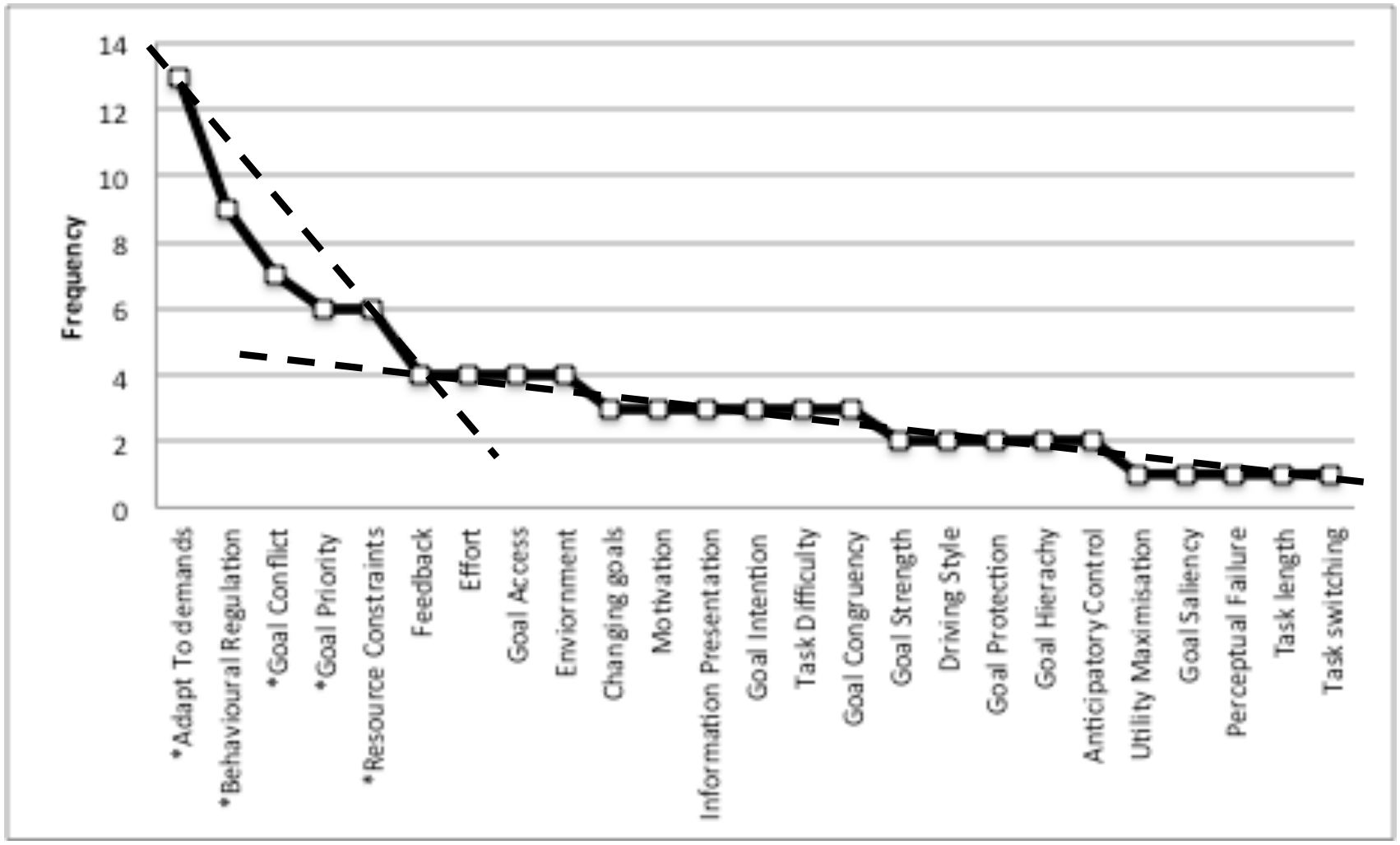

Figure 1. Scree plot showing the frequency of the factors in the literature. Dashed lines identify the top 5 factors as those of greatest importance, these are marked with (*).

\subsection{Factors}

The five key factors identified as the most prevalent in the literature are explored in more detail to determine how they provide an insight into the occurrence of distraction. As behaviour is heavily linked to context, the contextual factors that may implicate the outcome of events are also discussed with examples to demonstrate how adverse effects of distraction are linked to each factor.

\section{Factor 1: Adapt to demands}

Definition: "Adaptation refers to behavioural changes aimed to protect the main task goal in high task demand situations" (Cnossen, 2004: 219).

When faced with high mental load and complex situations drivers can adjust their behaviour in order to manage the situation. When interacting with a secondary task this often means slowing down, increasing time headway (Hosking et al, 2009) and/or reducing performance goals (Brookhuis et al, 1991). This has been shown with mobile phones (Rakauskas, et al., 2004), maps (Cnossen, 2004) and eco-driving (Young et al, 2011). Failure to adapt means no added safety margin is given when engaging in risky behaviours (Horrey \& Simons, 2007) 
Example: A driver's commute to work is heavily congested but they believe they can spare the attentional resources to reprogram the radio station. The driver may be aware this will heighten their risk of collision especially in heavy traffic so adapts to the increased demand of interacting with the secondary task by decreasing their speed and increasing their headway. Failing to slow down would minimise their time to respond to upcoming events, increasing their risk of collision.

\section{Factor 2: Behavioural Regulation}

Definition: The self-management of attention, effort, attitudes and emotions to facilitate goal attainment. A goal can be indicative of the behaviour of an individual trying to achieve it, and visa versa. The ability to regulate behaviour in line with the goals of the individual, the demands of the task and situation is key to maintaining safe driving performance.

Example: If the driver is in the vicinity of a police car they may be more motivated to regulate their driving behaviour in line with safety precautions and legal regulations for example, abiding speed limits, not talking on the phone, keeping to the inside lane, etc. When not under surveillance, safety goals may reduce and other goals may counter safe behaviour regulation. When in a hurry drivers may increase their speed, minimise headway and overtake other drivers to meet the goal of arriving at the destination sooner. Alternatively, boredom on long journeys drives drivers may increase their engagement with in-vehicle entertainment systems or make phone calls, overriding safety regulation to minimise boredom.

\section{Factor 3: Goal Conflict}

Definition: The existence of two or more goals that come into competition with each other such that both cannot be completed concurrently without disrupting one another. The degree of conflict depends on the level of shared resources required by the goals (Wickens, 2002; Salvucci \& Taategen, 2008) and how they are interchanged (Monk et al, 2004; Lee, 2014). To resolve conflicting goals it is necessary to either increase the resources available (Young \& Stanton, 2002), if possible, or inhibit other goals and focus only on that which is attainable (Robert \& Hockey, 1997). Inadequate goal selection based on inadequate resources has been linked with distraction (Trick et al, 2004; Patten et al, 2004; Regan et al, 2011).

Example: A driver is running late to a meeting so decides to send a text while driving to inform them they will arrive shortly. Texting will result in a conflict between looking at the road and the device and having the hands on the wheel or the phone. To manage the conflict the driver can choose not to send the text (inhibit the text goal) or pull over to send the text (inhibit the driving goal) or accept that 
engagement will mean a reduction in either or both tasks performance. The environmental context is likely to influence the decision e.g. heavy rain and surface water may reduce the willingness to engage both tasks at the same time, whereas long stretches of motorway on a clear day may increase willingness. Legislation and it's enforcement will also alter the readiness to engage in a distracting activity, if the driver thinks they are unlikely to get caught they will engage despite being aware of its illegitimacy and associated risks (Young \& Lenné, 2010).

\section{Factor 4: Goal Prioritisation}

Definition: Ordering the sequence of attending to goals depending on their perceived importance.

Different goals are relevant to different situations and therefore the priority of a goal is tied to the context. The multiple goals drivers face cannot be completed simultaneously, they therefore prioritise in accordance with their goal hierarchy (Dogan et al, 2011; Young et al, 2011). It is important that the priorities match the current demands.

Example: Employers that require employees to drive often supply company cars with in-built communication systems that enable them to be contactable at all times. An important call from the manager is likely to be determined by the individual as a high priority, motivating them to answer even if the environment is highly demanding. Other goals, including safety, may be demoted or compensated. Less important calls may not hold the same effect over the driver.

\section{Factor 5: Resource Constraints}

Definition: The limited or restricted access to visual, cognitive, auditory and/or physical resources required to perform the driving task effectively. Resources are finite; successful driver behaviour involves manipulating resources to enable their efficient distribution between tasks and according to the situational demands (Wierwille, 1993; Wickens, 2002; Lee et al, 2008).

Example: Selecting a song from a list on an mp3 player (portable or built in) requires high levels of visual monitoring and manual input to complete (Lee et al, 2012). Engaging in this task constrains the visual and manual resources available in the driving task to monitor the road and control the steering wheel. Effective timesharing of the visual resource requires successive glances back to the road to capture potential hazards and upcoming events while scanning the list of songs.

\subsection{Interconnections}

Safety arises from the complex interactions within a system (Leveson, 2004), therefore the interconnection are important in identifying how safety emerges. Applying a similar process to that 
used by Rafferty et al (2010), and in accordance with the grounded theory methodology, the literature was again reflected on to assess how the 5 factors identified above interrelate and safety emerges. Referring back to the 33 papers from which the 5 factors were acknowledged, factor interconnections were identified by observing any empirically tested connections made in the literature as well as associations made by authors in relating concepts to one another. The number of links between factors in the literature was then quantified to identify the strength of links within the literature. Connections between each of the key factors allows for a novel model to be developed that can depict how safety is impacted by in-vehicle technology use while driving. These connections are illustrated in Figure 2 which presents the Priority, Adapt, Resource, Regulate, Conflict (PARRC) model of distraction. This model, developed from the grounded theory approach, illustrates the key factors relating to distraction from in-vehicle technology and their interrelations as represented in literature from which it originates. The PARRC model offers a novel approach to the phenomena, with interconnecting factors used to inform on the potential for distraction across incidents. The interconnections may differ for specific distraction incidents, the complexity of the concept means that no two events are the same, however a generic formulation of the interconnections, as evident in the literature, is given.


Figure 2. The PARRC model of distraction from in-vehicle technology. The thickness of the lines suggests the number of the connections made within the literature, as identified in the key. 
The number of cited interconnections between factors was few, with some papers not showing any links between the 5 key factors. The interconnections should therefore be interpreted with some caution. The limited citation of some connections does however, lend itself to application of further research to evaluate and provide validation for the relationship between factors. Nonetheless, the following comments can be made.

Consistent with the multiple resource theory (Wickens, 2002) the PARRC model captures the requirement of adequate resource allocation for effective performance through the influential directional connections to all other elements in the model, with the exception of goal priority. It may be a result of the strong connection between goal conflict and goal prioritisation that prevents resources constraining the prioritised goal, however this would become clearer with an extended body of literature.

A prominent connection between 'goal conflict' and 'goal priority' is reflective of the need to solve a goal conflict through selecting the goal of highest importance to the individual, situation and/or demands. Without conflict there is no need to prioritise, as all goals would be able to run concurrently with no distractive effects (Wickens, 2002). The PARRC model suggests this through the impacting connection of resource constraints on goal conflict, suggesting that the resource availability limits the goals that may be concurrently engaged. In this respect it shares the notion of Fuller's (2000) TCI model, that capacity must meet demand for performance to succeed, although specifically focusing on capacity as the resources available.

The mechanism 'Adapt to Demands' is a heavily interconnected element of the model, which reflects the extensive literature on the adaption of behaviour in the presence of high task demands (e.g. Noy, 1989; Cnossen et al, 2000). The two-way relationship between 'goal conflict' and 'adapt to demands' is representative of the need to solve conflicts by adapting to demands but also that adaptions can create further conflicts between goals. For example, when slowing down to take a phone call the demand of the driving task is lowered to facilitate the phone call, however a conflicting goal to arrive at the destination on time is implicated and the time pressure goal needs readjusting. Thus, caution must be applied not to assume that adapting to meet certain demands resolves all issues, in fact it can cause more conflicts.

The connection between adapting to demands and prioritising is also consistent with a key concept of 
Hockey's (1997) compensatory control theory. Hockey (1997) states resolution of conflicts between goals should prioritise the main task of driving even if this may jeopardise other subsidiary tasks such as those relating to in-vehicle technology. The literature on driving with in-vehicle technology however, suggests that often drivers prioritise the secondary task while adapting the driving task e.g. taking a phone call from the manager but slowing down and reducing the speed goal (Rakauskas, et al., 2004). The PARRC model illustrates this through the bi-directional connection between 'goal priority' and 'adapt to demands'. Highlighting that prioritising the driving task requires adaption but also that adaption to incorporate a secondary task can alter priorities of the primary driving task. Appropriately prioritised tasks prevail without harm to driving performance, e.g. taking a phone call means slowing down but overall performance does not deteriorate. Yet, where prioritisation is given to a highly valued but highly demanding task drivers may be motivated to place themselves at high level of risk that they cannot adapt against. Hockey (1997) states that under these circumstances individuals may be able to increase their capacity to manage situations by employing compensatory effort. The relation between resource constraints and adapt to demand in the PARRC model supports the notion that adaption is related to the available resources. Therefore, the model explains the engagement with demanding secondary tasks as an adaption of the capacity to manage high workload that is motivated by effort. The absence of a connection between resource constraints and goal priority could therefore dictate that in order for drivers to prioritise a task in line with the available resources they must incur some form of adaption, either of task performance or effort related capacity to achieve the goal. The model is therefore somewhat consistent with the notion of compensatory control when faced with resource demanding situations whereby a prioritised goal stretches the capability of the driver but they are motivated to engage nonetheless.

The PAARC model also illustrates that salient cues in the environment can cause automatic triggering as they capture the drivers attention overriding top-down search strategies (Theeuwes 2004; Terry et al 2008), through the direct connection between goal conflict and behavioural regulation. This represents the manner through which the driving task is regulated while it is conflicting with a secondary invehicle task for attention. Awareness of environmental cues such as a changing traffic light or a car indicating to pull out have been shown to increase drivers resumption of the driving task at safety critical points, usually incurring sharp breaking (Jamson et al, 2004). Here no adaption occurs, but neither is it associated with a state of inattention as the driver still attains some level of awareness of the driving task to monitor the environmental cues. The PARRC model does not therefore suggest distraction results in a failure to attend to the driving tasks, but that there are mechanisms in place that 
help the driver restructure their behaviour to try and manage the driving task and concurrent technological secondary task. The way in which the mechanisms perform and the interconnections are realised are specific to each incident. The complexities of distraction must be accounted for by allowing flexibility in the way the model can explain events.

The PARRC model incorporates earlier theories of driving behaviour that highlight passive attentional capacities; the requirement for adequate resources (e.g. Wickens, 2002), and environmental cues that trigger critical events (Theeuwes, 2004). Yet it also incorporates more active mechanisms that relate to the capacity regulated goal engagement of the driver (Fuller, 2000) and their adaption in line with priorities (Hockey's, 1997). The model outlines the mechanisms of distraction, application of the PARRC model to a case study provides insight into the impact of systemic factors on these mechanisms.

\section{Application of the PARRC Model: A Case Study of distracted driving}

Grounded Theory is necessarily explorative in nature, thus in order to perform a preliminary exploration of the validity of the model its application to a real world example was conducted. The combined use of bottom-up and top-down testing is a way of assessing the model to determine its efficiency of representing real experiences (Gillham, 2000). Case studies are used frequently across multiple domains within human factors research to relate theoretical models and psychological factors to an in-depth analysis of naturalistic behaviour e.g. aviation (Plant \& Stanton, 2011), rail (Stanton \& Walker, 2011) and the military (Rafferty et al, 2010). This is especially true of large-scale accidents which, although rare, allow insight into system behaviour and the potential for failure. Single case studies, while limited by generalizability, have been recognised in the generation of theory, definition of concepts and in capturing the context surrounding phenomena (Darke et al, 1998). Furthermore, Hancock et al (2009) points out the benefits of individual cases in studying human-machine interactions.

To preliminary explore the potential validity of the PARRC model the case of Victoria McClure is used, as it is an example of the severe consequences of in-vehicle technology on road safety with a high level of public interest gathered by the press giving a detailed record of events. The courts portrayal of the 18-second period Victoria McClure took her eyes off the road caused her to serve a prison sentence for 'dangerous driving'. In line with the traditional individualistic approach, the court deemed the driver the sole offender, resulting in the heavy conviction. Applying a systems analysis aims to 
demonstrate wider systemic responsibility and an opportunity for novel countermeasures.

Figure 3 shows how each factor can explain the events in the lead up to the incident and the interconnections that facilitated the behaviour of Victoria McClure. The interconnections suggest how the performance of the system broke down and adverse safety implications emerged as Victoria McClure engaged in the navigation device for an extended period of time. Some of the system failures reside within the decisions and perceptions of Victoria McClure. For example, her failure to recognise the constraints the sat-nav task would have on her resources when she engaged in the task and established a goal conflict (event a), meant she put herself and other road users at danger as she failed to have enough resources to regulate the driving task efficiently. Furthermore, her failure to reprioritise the driving task (event f), regulating her attention towards the sat-nav over the 18 -second period, also support the claims of the court that she was 'driving dangerously'. These events illustrate the considerations of the court. The authors believe that applying the systems approach to the PARRC model can highlight failures with the system as a whole that lead to the incident. 


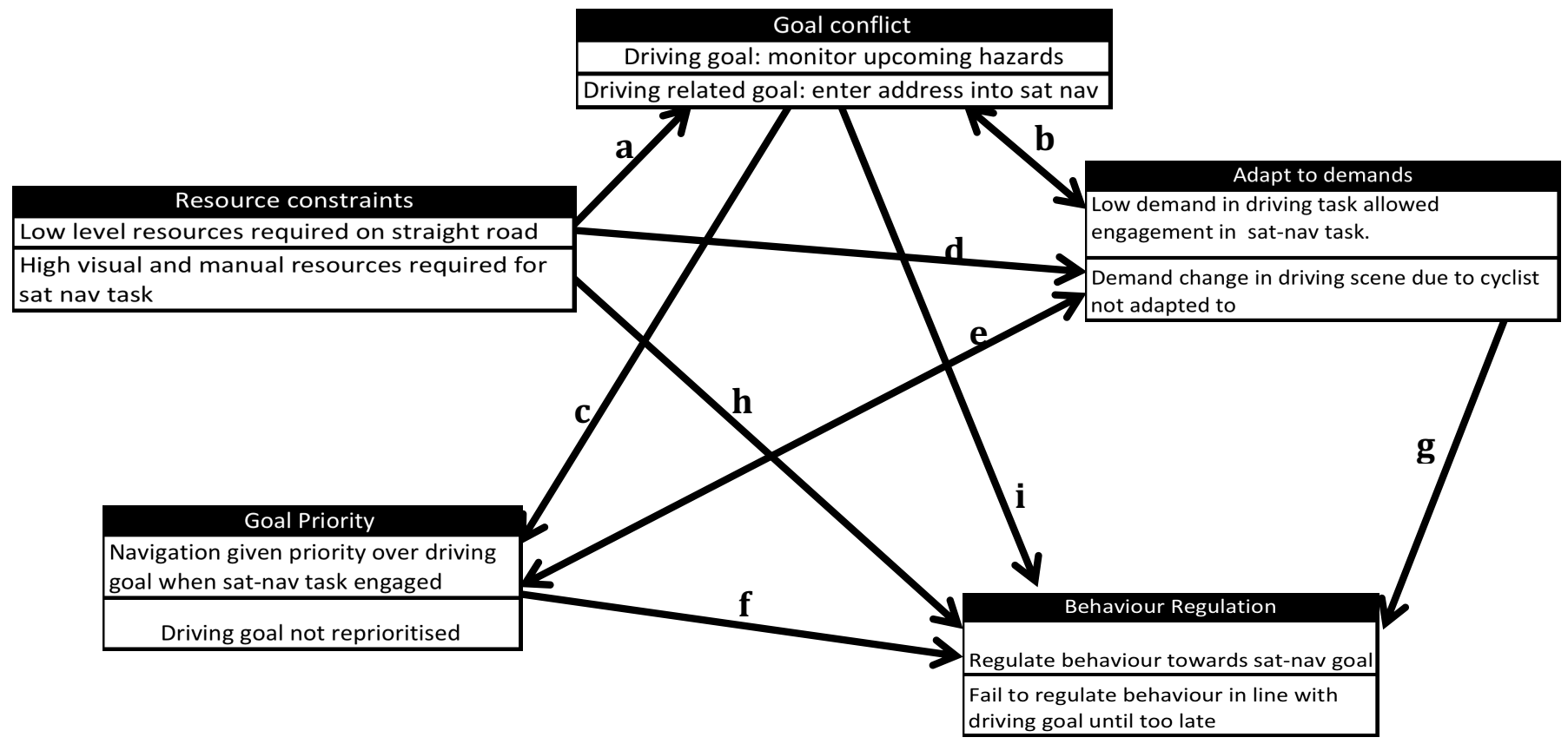

\begin{tabular}{|l|l|}
\hline Event & Description \\
\hline a & $\begin{array}{l}\text { When driving on a straight road spare visual, motor and cognitive resources } \\
\text { facilitated engagement with the sat-nav goal. The addition of this goal results in a } \\
\text { conflict as resources are taken away from the driving task. }\end{array}$ \\
\hline $\mathrm{b}$ & $\begin{array}{l}\text { Conflict requires adaption of either or both tasks. } \\
\text { Demand of road judged to be easy so reduce driving performance goal and engage in } \\
\text { the secondary task goal. }\end{array}$ \\
\hline $\mathrm{c}$ & $\begin{array}{l}\text { Conflict between driving and sat-nav goal resolved by giving priority to sat-nav goal } \\
\text { as determined by the reduced resources required by low driving demands. }\end{array}$ \\
\hline $\mathrm{d}$ & $\begin{array}{l}\text { Visual, manual and cognitive resources engaged in sat-nav goal, none directed } \\
\text { towards the road therefore fail to notice new demand in the driving scene imposed by } \\
\text { the cyclist. }\end{array}$ \\
\hline $\mathrm{e}$ & $\begin{array}{l}\text { Cyclist not seen so driving task not reprioritised. Failure to prioritise to driving task } \\
\text { to glance back to the road means the cyclist cannot be adapted to. }\end{array}$ \\
\hline $\mathrm{g}$ & $\begin{array}{l}\text { Failure to reprioritise causes behaviour to be regulated in line with the sat-nav goal. } \\
\text { The driving goal received no visual glances or cognitive interaction. }\end{array}$ \\
\hline $\mathrm{h}$ & $\begin{array}{l}\text { Low driving demand and high sat-nav demand meant behaviour was adapted to } \\
\text { regulate the sat-nav goal. }\end{array}$ \\
\hline $\mathrm{i}$ & $\begin{array}{l}\text { Visual resources are constrained by the sat-nav task, behaviour is regulated in line } \\
\text { with these constraints to achieve the sat-nav goal while ignoring the driving goal. } \\
\text { behaviour efficiently to resolve, the sat nav goal was achieved but the driving goal } \\
\text { was not regulated efficiently. }\end{array}$ \\
\hline
\end{tabular}

Figure 3. The PARRC Model showing each of the factors involved in the case study incident and the interconnecting events referenced in the table that occurred leading up to the incident 


\subsection{The Systems Approach and The PARRC Model}

Rasmussen's (1997) risk management theory suggests that elements across 6 hierarchical levels interact with each other to influence system performance and the emergence of safety. Young \& Salmon (2015) highlight the application of each of these levels to driver distraction. They state that the government at the top level puts in place policies and legislation that are then publicised by the media and enforced by police. The regulatory bodies must then influence vehicle manufacturers, road designers and aftermarket device companies to abide the laws before they expose the driver to the in-vehicle equipment and roads they must use. The surrounding environment is included at the bottom level of the system as its changing conditions alter how the driver manages their behaviour in a bottom-up manner, for example the water on the road forces drivers to slow down. The basis of Rasmussen's (1997) theory states that elements across these levels have an input into the events that occur. Further exploration of the case study of Victoria McClure considered the potential impacts of wider systemic factors as initially suggested by Salmon \& Young (2015). The outcome of this exploration is illustrated in figure 4 and discussed below.



Figure 4. The PARRC model of distraction from in-vehicle technology with the wider system elements impacting on the mechanisms that broke down in the case of Victoria McClure. 


\subsubsection{Goal Conflict}

Reason's (2000) approach to systems error states adverse events occur due to the continuation of activities in conditions that are undesirable but were permitted by the system. Ultimately, Victoria McClure engaged with the sat-nav whilst driving because the device permitted her to do so by government policy that allows such devices to be road legal and conflict with the driving task for the driver attention. It was also permitted by the HMI manufacture who chose to design the device for use in-motion. Placing the device in conflict with the driving task is thus an initial failure of the system that resulted in the incident.

Sat-Navs are now a necessity for many drivers and their willingness to engage with them while driving is high (Jensen et al, 2010; Cnossen et al, 2004). However, this case study shows that government policy and manufacturers should consider the demands they place on drivers by allowing devices to be in conflict for the drivers' attention while in motion. It is evident that drivers are willing to compromise safety to engage with devices where they are permitted. Some manufacturers have started to prevent the user from interacting with the device while the vehicle is in motion (e.g. Lexus and Toyota). Yet other manufacturers often allow devices to be driver initiated and in doing so hand the responsibility of engaging with the device while driving to the driver. The liability of the manufacturer is removed by stating guidelines on use, removing themselves from a position of responsibility, even if these are not actively enforced. More needs to be done across the system to insist the same approach is adopted by all. This requires more top down control in the form of policy on what is and is not permissible for use when driving in order to protect the driver and the safety of the transport system. This requires a clearer notion of the drivers' capabilities while driving.

Workload managers are used by some manufacturers as they act as a countermeasure to this by inhibiting interaction at inappropriate times (see Green 2004 for a review). Workload is a measure heavily linked to distraction and workload management systems operate by sensing high workload driving situations, such as at intersections, and block any unnecessary and highly demanding tasks, for example diverting incoming phone calls to answerphone. Such devices limit the distractive potential of highly demanding secondary tasks (Green, 2004)

\subsubsection{Resource Constraints}

The case study illustrates the high visual and manual resource demand of the task 'destination entry', as evidenced in the literature, which led the driver to 'drive blind' for 18 seconds. In a comparison of time 
to complete different in-vehicle tasks, Harvey and Stanton (2013) showed that entering an address into a navigation system resulted in the longest task time of all in-vehicle system tasks tested, with maximum and median response times well above the 15-seconds recommended limit for in-vehicle tasks (Green, 1999, Society for Automotive Engineers, 2002). Such research should be used to inform legislation and manufacturer design against placing highly dangerous tasks into the vehicle to tempt drivers. Manufacturers and developers of devices should design with the users limitations in mind (Larsson, et al, 2010). Human resources are finite (Wickens 2002; Salvucci \& Taatgen, 2008), thus utilisation of resources other then the visual or manual resources that are critical to the driving task may have allowed visual attention to the road to be minimally effected by the secondary task for example, speech based input (Ranney et al, 2000).

Another factor impacting the spare resources of the driver is the road infrastructure in the surrounding environment. At the point of the incident in the case study the driver was on a long straight road which demands a low level of the drivers visual resources to manage, freeing up resources for the secondary task. In this case it led the driver into a false sense of security and she failed to update her forward view and spot the cyclist. Yet, if a cycle lane had been present the cyclist would be better protected from other road users and the driver would be alerted to potential cyclists appearing up ahead enabling them to allocate their resources in line with this, perhaps determining this to be a less appropriate place to interact with secondary tasks.

\subsubsection{Adapt to Demands}

As previously mentioned, the straight road lowered the demands of the driving task which is linked with the decision to engage with the device in figure 3 (e.g. events a,b,c and g). There was also high visibility and low traffic demands due to it being a Sunday morning in a rural area, freeing the drivers' resources to engage in the sat-nav task. Adapting to these low driving demands enabled engagement with the secondary task and consequently reduced the priority of the driving goal, resulting in a failure to monitor and adapt to the cyclist. If the weather conditions had been less clear, or if there was more traffic on the roads, the demand of the driving task would have increased and Victoria McClure may not have chosen to engage with the sat-nav at that time. Furthermore, in Victoria McClure's defence the cyclist was believed to have low visibility clothing on that prevented him from being seen. Had the

cyclist been wearing brighter clothing he may have been more salient, capturing the attention of Victoria McClure and triggering a reaction. The Highway Code advises the use of highly visible clothing in daylight but there are no laws surrounding this. Indeed one outcome of this event is the need 
for increased cyclist awareness on the roads.

\subsection{Goal Priority}

The court suggest the driver to be at fault for failing to reprioritise the driving task. Taking a systems approach, figure 4 suggests government education providers and the media may also hold some responsibility for not fully informing the driver of the implications involved in engaging with the navigation system. Fuller's (2000) TCI Theory highlights the connection between perceived demands and capability when deciding to engaging with tasks. Fully informing drivers of the demands may lessen the potential to interact with navigation systems while driving. The adverse effects of interacting with handheld mobile phones have been widely countered by legislation and widespread media campaigns to increase awareness of the adverse effects of using phones behind the wheel. The adverse effects of using a sat-nav while driving are less well publicised. Sat-navs are now commonplace in vehicles, often incorporated into vehicle design itself, their assistance with the driving task may reduce their perceived distractive potential and heighten perceptions on capability to use. Research has shown their adverse effects (Harvey \& Stanton, 2011), therefore education providers and media campaigns have a responsibility to publicise these consequences.

It is important to note that developments of in-vehicle technology are not all negatively associated with safety. Forward collision warning systems are increasingly being installed by manufactures to warn drivers if they are approaching another road user or object at an unsafe speed and autonomous emergency brake features aim to increase the safety of the driver and road system (Banks \& Stanton 2015). Where salient cues in the environment are not recognised, these systems highlight them to the driver so they can reprioritise their goals appropriately. Such a system was not incorporated into Victoria McClure's vehicle otherwise it would have alerted her to the upcoming cyclist when detected, allowing her to glance up from the road, notice the cyclist and reprioritise the driving task and slow down to pass the cyclist safely. The lack of skid marks on the road evidence that she did not spot the cyclist and perform an emergency brake. The opportunity of vehicle manufacturers to implicate warning systems and autonomous facilities to adapt driving performance to the demands of the roadway is shown on figure 4.

\section{Behavioural Regulation}

The driver is ultimately the determinant of how they regulate their behaviour and, as this easily inferred through capturing the drivers' behaviour, legislation focuses on the drivers' responsibility (Tingvall et 
al, 2009). Yet, drivers are forced to regulate their behaviour in line with the wider systems factors that are imposed on them. It is evident from this case study that the driver chose to regulate their behaviour in favour of the sat-nav goal rather then prioritising the driving task to spot the driver however, as figure 4 identifies, there is an array of factors impacting on this.

Does this therefore suggest that Victoria McClure was not wholly to blame but in fact many other factors in the system failed to protect her and the cyclist? It is hard to determine who is ultimately to blame, nor is it always wise to seek blame (Leveson, 2004) but it is evident that responsibility should not always be wholly attributed to the driver. Exploration of the PARRC model using a case study provides an initial insight into the wider system surrounding driver distraction from in-vehicle technology. In doing so it highlights responsibility for failures that are often passed on to driver, as attributable to the system as a whole.

\section{General Discussion}

\subsection{Theoretical implications}

Applying the grounded theory approach to the literature on in-vehicle technology as a source of distraction has enabled key mechanisms to be identified and their interrelations established into the PARRC model. The mechanisms share commonalties to adaption theories and the role of prioritisation suggested by Hockey (1997). It highlights the active role of the driver as they apply strategies to manage the driving task alongside the secondary task. Yet it also relates to the limited human attention capacity which limits the number and type of goals that drivers can engage with (Wickens 2002; Theeuwes, 2004). The multiple goals available require prioritisation, with the relevance of safety fundamental to system success. Cases like Victoria McClure's suggests that the main task goal (arriving at the destination safely) is not always given appropriate priority. The PARRC model gives flexibility as to why this occurs yet, importantly, it also allows for insights into the role of other elements of the road-transport system. No previous model has been able to account for the impact of wider systems factors in distraction. In order to move away from individual-centred approaches, the role of systems factors needs to be identified. Utilising the PARRC model, this can be illustrated on a customised case basis.

\subsection{Practical implications}

Applying the PARRC model to the case of Victoria McClure has preliminary shown its ability to account for the impact of the wider road transport systems on the underlying mechanisms of distraction 
from in-vehicle technology (Figure 4). Although some causes of distraction may be attributed to the driver, such as their motivation and beliefs about the risks of engaging with secondary tasks, there is a strong argument to suggest sources outside of the driver may hold some responsibility (Young \& Salmon 2015). Elements at the top of Rasmussen's (1997) systems hierarchy i.e. government policy and regulations, play a large role in altering perspectives that feed down to the lower levels of the system as policy is adopted. This paper has highlighted the role government legislation has on the potential for in-vehicle technologies and portable devices to be used by drivers. Legislation against the use of handheld mobile phones, informed by research on its adverse effects on driving, has impacts throughout the road transport system with media campaigns raising awareness of the risks and manufacturers developing hands-free devices as an alternative. The same is not true of other devices such as navigation aids, despite convincing research on their distractive effects (Harvey \& Stanton, 2011; Harvey \& Stanton, 2013). With more devices being used by drivers, legislation needs to play a more active role in preventing the implementation of technology that has not been fully tested for its distractive effects. Increasing awareness of the risks devices have on safety, and improving design of interfaces to reduce the resources they constrain are some of the potential countermeasure identified in the an explorative case study using the PARRC model.

\section{Conclusions}

Developments in technology have facilitated a large opportunity for its widespread use in-vehicles, however the utility of such devices needs to be balanced against potential safety implications, as they divert the drivers attention away from the main driving task. The PARRC model offers a way of identifying the underlying mechanisms that determine performance while interacting with in-vehicle devices. The application of the PARRC model to a systems approach of distraction is explored to highlight the impact of high-level policy developers and regulators on safety emergence. The need to target the underlying cause of distraction from in-vehicle devices does not relate to the current individual focused approach. Instead an approach that unites all systemic elements is called for. Further research is required to further test the model beyond the case study presented in this paper to validate the factors and their interconnections that have been identified from the grounded theory approach. It is hoped this will raise further countermeasures in line with systems thinking.

\section{Acknowledgements}

This research was funded by the Engineering and Physical Science Research Council (EPSRC) and Jaguar Land Rover. 


\section{References}

Alm, H., \& Nilsson, L. (1995). The effects of a mobile telephone task on driver behaviour in a car following situation. Accident Analysis \& Prevention, 27(5), 707-715.

Banks, V. A., \& Stanton, N. A. (2015). Contrasting models of driver behaviour in emergencies using retrospective verbalisations and network analysis. Ergonomics, (ahead-of-print), 1-10.

BBC News, (2013) Cyclist Anthony Hilson death: Victoria McClure jailed. Online source available at: http://www.bbc.co.uk/news/uk-england-berkshire-23904694 (date accessed: 21/08/2015).

Brookhuis, K. A., de Vries, G., \& de Waard, D. (1991). The effects of mobile telephoning on driving performance. Accident Analysis \& Prevention, 23(4), 309-316.

Brown ID, Tickner AH, Simmonds DCV. Interference between concurrent tasks of driving and telephoning. Journal of Applied Psychology. 1969;53(5):419-424.

Cassano-Piche, A. L., Vicente, K. J., \& Jamieson, G. A. (2009). A test of Rasmussen's risk management framework in the food safety domain: BSE in the UK. Theoretical Issues in Ergonomics Science, 10(4), 283-304.

Cavaye, A. L. (1996). Case study research: a multi-faceted research approach for IS. Information systems journal, 6(3), 227-242.

Cnossen, F., Rothengatter, T., \& Meijman, T. (2000). Strategic changes in task performance in simulated car driving as an adaptive response to task demands. Transportation research part $F$ : traffic psychology and behaviour, 3(3), 123-140.

Cnossen, F., Meijman, T., \& Rothengatter, T. (2004). Adaptive strategy changes as a function of task demands: a study of car drivers. Ergonomics, 47(2), 218-236. doi: 10.1080/00140130310001629757

Darke, P., Shanks, G., \& Broadbent, M. (1998). Successfully completing case study research: combining rigour, relevance and pragmatism. Information systems journal, 8(4), 273-289.

Dekker, S. (2011). Drift into Failure: From Hunting Broken Components to Understanding Complex Systems.

Dingus, T. A., Klauer, S., Neale, V., Petersen, A., Lee, S., Sudweeks, J., \& Gupta, S. (2006). The 100car naturalistic driving study, Phase II-results of the 100-car field experiment.

Dogan, E., Steg, L., \& Delhomme, P. (2011). The influence of multiple goals on driving behavior: The case of safety, time saving, and fuel saving. Accident Analysis \& Prevention, 43(5), 1635-1643.

Donmez, B., Boyle, L. N., \& Lee, J. D. (2008). Mitigating driver distraction with retrospective and concurrent feedback. Accident Analysis \& Prevention, 40(2), 776-786.

Fuller, R. (2000). The task-capability interface model of the driving process. Recherche-TransportsSécurité, 66, 47-57. 
Gillham, B. (2000). Case study research methods. Bloomsbury Publishing.

Glaser, B.G. (2001). The Grounded Theory Perspective: Conceptualization Contrasted with Description. Mill Valley, Ca.: Sociology Press.

Glaser, B., \& Strauss, A. (1967). The discovery grounded theory: strategies for qualitative inquiry. Aldin, Chicago.

Green, P. (1999). The 15-second rule for driver information systems. ITS America Ninth Annual Meeting, Conference Proceedings (CD-ROM). Washington, D.C.: Intelligent Transportation Society of America.

Green, P. (2004). Driver Distraction, Telematics Design, and Workload Managers: Safety Issues and Solutions (No. 2004-21-0022). SAE Technical Paper.

Groeger, J. A. (2000). Understanding driving: Applying cognitive psychology to a complex everyday task: Psychology Press.

Hancock, P. A., Lesch, M., \& Simmons, L. (2003). The distraction effects of phone use during a crucial driving maneuver. Accident Analysis \& Prevention, 35(4), 501-514.

Hancock, P. A., Hancock, G. M., \& Warm, J. S. (2009). Individuation: the N=1 revolution. Theoretical Issues in Ergonomics Science, 10(5), 481-488.

Harms, L., \& Patten, C. (2003). Peripheral detection as a measure of driver distraction. A study of memory-based versus system-based navigation in a built-up area. Transportation Research Part F: Traffic Psychology and Behaviour, 6(1), 23-36.

Harvey, C., Stanton, N. A., Pickering, C. A., McDonald, M., \& Zheng, P. (2011). A usability evaluation toolkit for in-vehicle information systems (IVISs). Applied ergonomics, 42(4), 563-574.

Harvey, C., \& Stanton, N. A. (2013). Usability evaluation for in-vehicle systems. Crc Press.

Hockey, G.R.J. (1997). Compensatory control in the regulation of human performance under stress and high work-load: A cognitive-energetical framework. Biological Psychology, 45, 73-93.

Horrey, W. J., \& Simons, D. (2007). Examining cognitive interference and adaptive safety behaviours in tactical vehicle control. Ergonomics, 50(8), 1340-1350.

Horrey, William J., Mary F. Lesch, and Angela Garabet. "Assessing the awareness of performance decrements in distracted drivers." Accident Analysis \& Prevention 40, no. 2 (2008): 675-682.

Hosking, S. G., Young, K. L., \& Regan, M. A. (2009). The effects of text messaging on young drivers. Human Factors: The Journal of the Human Factors and Ergonomics Society, 51(4), 582-592.

Jamson, A. H., Westerman, S. J., Hockey, G. R. J., \& Carsten, O. M. (2004). Speech-based e-mail and driver behavior: Effects of an in-vehicle message system interface. Human Factors: The Journal of the Human Factors and Ergonomics Society, 46(4), 625-639. 
Jensen, B. S., Skov, M. B., \& Thiruravichandran, N. (2010). Studying driver attention and behaviour for three configurations of GPS navigation in real traffic driving. In Proceedings of the SIGCHI Conference on Human Factors in Computing Systems (pp. 1271-1280). ACM.

Kircher, K., Fors, C., \& Ahlstrom, C. (2014). Continuous versus intermittent presentation of visual ecodriving advice. Transportation Research Part F: Traffic Psychology and Behaviour, 24, 27-38.

Lansdown, T. C., Stephens, A. N., \& Walker, G. H. (2015). Multiple driver distractions: a systemic transport problem. Accident Analysis \& Prevention, 74, 360-367.

Larsson, P., Dekker, S. W., \& Tingvall, C. (2010). The need for a systems theory approach to road safety. Safety Science, 48(9), 1167-1174.

Layder, D. (1998). Sociological practice: Linking theory and social research. Sage.

Lee, J. D. (2014). Dynamics of Driver Distraction: The process of engaging and disengaging. Annals of Advances in Automotive Medicine, 58, 24-32.

Lee, J. D., Hoffman, J. D., \& Hayes, E. (2004). Collision warning design to mitigate driver distraction. In Proceedings of the SIGCHI conference on human factors in computing systems (pp. 65-72). ACM.

Lee, J. D., Young, K. L., \& Regan, M. A. (2008). Defining driver distraction. Driver distraction: Theory, effects and mitigation, 31-40.

Lee, J. D., Roberts, S. C., Hoffman, J. D., \& Angell, L. S. (2012). Scrolling and Driving How an MP3 Player and Its Aftermarket Controller Affect Driving Performance and Visual Behavior. Human Factors: The Journal of the Human Factors and Ergonomics Society, 54(2), 250-263.

Lerner, N., Singer, J., \& Huey, R. (2008). Driver Strategies for Engaging in Distracting Tasks Using In-Vehicle Technologies. Report No. DOT HS 810 919. US Department of Transportation, Washington, DC.

Leveson, N. (2004). A new accident model for engineering safer systems. Safety science, 42(4), 237270.

Leveson, N. (2011). Engineering a safer world: Systems thinking applied to safety. Mit Press.

Liang, Y., \& Lee, J. D. (2010). Combining cognitive and visual distraction: Less than the sum of its parts. Accident Analysis \& Prevention, 42(3), 881-890.

McCartt, A. T., Hellinga, L. A., \& Bratiman, K. A. (2006). Cell phones and driving: review of research. Traffic injury prevention, 7(2), 89-106.

Mitsopoulos-Rubens, E., Trotter, M. J., \& Lenné, M. G. (2011). Effects on driving performance of interacting with an in-vehicle music player: A comparison of three interface layout concepts for information presentation. Applied ergonomics, 42(4), 583-591. 
Monk, C. A., Boehm-Davis, D. A., Mason, G., \& Trafton, J. G. (2004). Recovering from interruptions: Implications for driver distraction research. Human Factors: The Journal of the Human Factors and Ergonomics Society, 46(4), 650-663.

Moray, N. 1999, The psychodynamics of human-machine interaction, in D. Harris (ed.), Engineering Psychology and Cognitive Ergonomics, Vol. 4 (Aldershot, UK: Ashgate), 225-235.

Musselwhite, C. B. A., \& Haddad, H. (2010). Exploring older drivers' perceptions of driving. European Journal of Ageing, 7(3), 181-188. doi: 10.1007/s10433-010-0147-3

Noy, Y. I. (1989). Intelligent route guidance: will the new horse be as good as the old?. In Vehicle Navigation and Information Systems Conference, 1989. Conference Record (pp. 49-55). IEEE.

Office for National Statistics (2013). Crime in England and Wales, period ending September 2013. Released 23 January 2014. http://www.ons.gov.uk/ons/rel/crime-stats/crime-statistics/index.html

Olsen, E. C. B., Lerner, N., Perel, M., \& Simons-Morton, B. G. (2005). In-car electronic device use among teen drivers. In Transportation Research Board Meeting, Washington, DC.

Patten, C. J., Kircher, A., Östlund, J., \& Nilsson, L. (2004). Using mobile telephones: cognitive workload and attention resource allocation. Accident Analysis \& Prevention, 36(3), 341-350.

Plant, K. L., \& Stanton, N. A. (2012). Why did the pilots shut down the wrong engine? Explaining errors in context using Schema Theory and the Perceptual Cycle Model. Safety science, 50(2), 300-315.

RAC (2013). RAC Motoring Report 2013. RAC Foundation for Motoring and the Environment. http://www.rac.co.uk/RAC/files/5b/5bfb0586-d8d9-41f6-b8a2-896b45b38cb3.pdf

Rafferty, L. A., Stanton, N. A., \& Walker, G. H. (2010). The famous five factors in teamwork: a case study of fratricide. Ergonomics, 53(10), 1187-1204.

Rakauskas, M. E., Gugerty, L. J., \& Ward, N. J. (2004). Effects of naturalistic cell phone conversations on driving performance. Journal of Safety Research, 35(4), 453-464. doi: 10.1016/j.jsr.2004.06.003

Ranney, T. A., Mazzae, E., Garrott, R., \& Goodman, M. J. (2000). NHTSA driver distraction research: Past, present, and future. In Driver Distraction Internet Forum (Vol. 2000).

Rasmussen, J. (1997). Risk management in a dynamic society: a modelling problem. Safety science, 27(2), 183-213.

Reason, J. (2000). Human error: models and management. Bmj, 320(7237), 768-770.

Redelmeier, D. A., \& Tibshirani, R. J. (1997). Association between cellular-telephone calls and motor vehicle collisions. New England Journal of Medicine, 336(7), 453-458.

Regan, M. A., Young, K. L., Lee, J. D., \& Gordon, C. P. (2009). Sources of driver distraction (pp. 249279). CRC Press, Taylor \& Francis Group. 
Regan, M. A., Hallett, C., \& Gordon, C. P. (2011). Driver distraction and driver inattention: Definition, relationship and taxonomy. Accident Analysis \& Prevention, 43(5), 1771-1781.

Robert, G., \& Hockey, J. (1997). Compensatory control in the regulation of human performance under stress and high workload: A cognitive-energetical framework. Biological psychology, 45(1), 73-93.

Salmon, P. M., McClure, R., \& Stanton, N. A. (2012). Road transport in drift? Applying contemporary systems thinking to road safety. Safety Science, 50(9), 1829-1838. doi: 10.1016/j.ssci.2012.04.011

Stanton, N. A., \& Walker, G. H. (2011). Exploring the psychological factors involved in the Ladbroke Grove rail accident. Accident Analysis \& Prevention, 43(3), 1117-1127.

Salvucci, D. D., \& Taatgen, N. A. (2008). Threaded cognition: An integrated theory of concurrent multitasking. Psychological Review, 115(1), 101-130. doi: 10.1037/0033-295x.115.1.101

Sheridan, T. B. (2004). Driver distraction from a control theory perspective. Human Factors: The Journal of the Human Factors and Ergonomics Society, 46(4), 587-599.

Society of Automotive Engineers (2002), Calculation of the time to complete in-vehicle navigation and route guidance tasks (SAE recommended practice J2365). Warrendale, PA: Society of Automotive Engineers.

Stanton, N. A., \& Salmon, P. M. (2009). Human error taxonomies applied to driving: A generic driver error taxonomy and its implications for intelligent transport systems. Safety Science, 47(2), 227-237. doi: 10.1016/j.ssci.2008.03.006

Strauss, A., \& Corbin, J. (1994). Grounded theory methodology. Handbook of qualitative research, 273-285.

Terry, H. R., Charlton, S. G., \& Perrone, J. A. (2008). The role of looming and attention capture in drivers' braking responses. Accident Analysis \& Prevention, 40(4), 1375-1382.

Theeuwes, J. (2004). Top-down search strategies cannot override attentional capture. Psychonomic bulletin \& review, 11(1), 65-70.

Tingvall, C., Ekstein, L., Hammer, M. (2009) Government and industry perspectives on driver distraction. In M.A. Regan, J.D. Lee, K.L. Young (Eds.), Driver distraction: Theory, Effects and Mitgation, CRC Press, Boca Raton, FL (2009)

Trick, L. M., Enns, J. T., Mills, J., \& Vavrik, J. (2004). Paying attention behind the wheel: A framework for studying the role of attention in driving. Theoretical Issues In Ergonomics Science, 5(5), $385-424$.

Vrkljan, B. H., \& Polgar, J. M. (2007). Driving, navigation, and vehicular technology: experiences of older drivers and their co-pilots. Traffic injury prevention, 8(4), 403-410. doi: $10.1080 / 15389580701576423$

Walker, G. H., Stanton, N. A., \& Salmon, P. (2015). Human Factors in Automotive Engineering and Design. (Human Factors in Transport Series). Farnham, UK: Ashgate Publishing Ltd. 
Wickens, C. D. (2002). Multiple resources and performance prediction. Theoretical Issues In Ergonomics Science, 3(2), 159-177.

Wierwille, W. W. (1993). Demands on driver resources associated with introducing advanced technology into the vehicle. Transportation Research Part C: Emerging Technologies, 1(2), 133-142.

Young, M. S., \& Stanton, N. A. (2002). Malleable attentional resources theory: a new explanation for the effects of mental underload on performance. Human Factors: The Journal of the Human Factors and Ergonomics Society, 44(3), 365-375.

Young, K., Regan, M., \& Hammer, M. (2007). Driver distraction: A review of the literature. Distracted driving. Sydney, NSW: Australasian College of Road Safety, 379-405.

Young, K. L., \& Lenné, M. G. (2010). Driver engagement in distracting activities and the strategies used to minimise risk. Safety Science, 48(3), 326-332. doi: 10.1016/j.ssci.2009.10.008

Young, M. S., Birrell, S. A., \& Stanton, N. A. (2011). Safe driving in a green world: A review of driver performance benchmarks and technologies to support 'smart' driving. Applied ergonomics, 42(4), 533539. doi: 10.1016/j.apergo.2010.08.012

Young, K. L., \& Salmon, P. M. (2012). Examining the relationship between driver distraction and driving errors: A discussion of theory, studies and methods. Safety science, 50(2), 165-174.

Young, K. L., Salmon, P. M., \& Cornelissen, M. (2013). Distraction-induced driving error: An on-road examination of the errors made by distracted and undistracted drivers. Accident Analysis \& Prevention, $58,218-225$.

Young, K. L., \& Salmon, P. M. (2015). Sharing the responsibility for driver distraction across road transport systems: A systems approach to the management of distracted driving. Accident Analysis \& Prevention, 74, 350-359. 
Appendix A. Table containing details of 33 articles used in the grounded theory literature analysis in the development of the PARRC Model.

\begin{tabular}{|c|c|c|c|c|}
\hline Author(s) & Date & Title & Publication & Factor(s) Identified \\
\hline Berg, H. Y. & 2006 & $\begin{array}{l}\text { Reducing crashes and injuries among young } \\
\text { drivers: what kind of prevention should we } \\
\text { be focusing on? }\end{array}$ & $\begin{array}{l}\text { Journal: Injury prevention : Journal of } \\
\text { the International Society for Child and } \\
\text { Adolescent Injury Prevention }\end{array}$ & Changing Goals \\
\hline $\begin{array}{l}\text { Birrell, S. A., } \\
\text { Young M.S., } \\
\text { Jenkins D.P.\& } \\
\text { Stanton N.A. }\end{array}$ & 2011 & $\begin{array}{l}\text { Cognitive work analysis for safe and efficient } \\
\text { driving }\end{array}$ & $\begin{array}{l}\text { Journal: Theoretical Issues in } \\
\text { Ergonomics Science }\end{array}$ & Goal Priority; Feedback \\
\hline Blomquist, G. & 1986 & $\begin{array}{l}\text { A utility maximization model of driver traffic } \\
\text { safety behaviour. }\end{array}$ & $\begin{array}{l}\text { Journal: Accident Analysis and } \\
\text { Prevention }\end{array}$ & $\begin{array}{l}\text { Adapt To Demands; Resource } \\
\text { Constraints; Behavioural Regulation; } \\
\text { Utility Maximisation; } \\
\text { Effort }\end{array}$ \\
\hline $\begin{array}{l}\text { Brookhuis K.A., } \\
\text { de Vries G. \& } \\
\text { de Waard D. }\end{array}$ & 1991 & $\begin{array}{l}\text { The effects of mobile telephoning on driving } \\
\text { performance }\end{array}$ & $\begin{array}{l}\text { Journal: Accident Analysis and } \\
\text { Prevention }\end{array}$ & $\begin{array}{l}\text { Resource Constraints; Adapt To } \\
\text { Demands }\end{array}$ \\
\hline $\begin{array}{l}\text { Cnossen F., } \\
\text { Meijman T. \& } \\
\text { Rothengatter T. }\end{array}$ & 2004 & $\begin{array}{l}\text { Adaptive strategy changes as a function of } \\
\text { task demands: a study of car drivers. }\end{array}$ & Journal: Ergonomics & $\begin{array}{l}\text { Adapt To Demands; Goal Conflict; } \\
\text { Goal Priority; Motivation; } \\
\text { Information Presentation }\end{array}$ \\
\hline $\begin{array}{l}\text { Dogan E., Steg } \\
\text { L. \& } \\
\text { Delhomme P. }\end{array}$ & 2011 & $\begin{array}{l}\text { The influence of multiple goals on driving } \\
\text { behavior: the case of safety, time saving, and } \\
\text { fuel saving. }\end{array}$ & $\begin{array}{l}\text { Journal: Accident Analysis and } \\
\text { Prevention }\end{array}$ & $\begin{array}{l}\text { Goal Conflict; Goal Priority; } \\
\text { Behavioural Regulation; Feedback; } \\
\text { Goal Saliency }\end{array}$ \\
\hline $\begin{array}{l}\text { Elliott, M. A. \& } \\
\text { Armitage C. J. }\end{array}$ & 2006 & $\begin{array}{l}\text { Effects of implementation intentions on the } \\
\text { self-reported frequency of drivers' } \\
\text { compliance with speed limits }\end{array}$ & $\begin{array}{l}\text { Journal: Journal of Experimental } \\
\text { Psychology-Applied }\end{array}$ & $\begin{array}{l}\text { Goal Intentions; Goal Access; Goal } \\
\text { Strength }\end{array}$ \\
\hline $\begin{array}{l}\text { Engstrom J., } \\
\text { Johansson E. \& } \\
\text { Ostlund J. }\end{array}$ & 2005 & $\begin{array}{l}\text { Effects of visual and cognitive load in real } \\
\text { and simulated motorway driving }\end{array}$ & $\begin{array}{l}\text { Journal: Transportation Research Part } \\
\text { F: Traffic Psychology and Behaviour }\end{array}$ & $\begin{array}{l}\text { Resource Constraints; Adapt To } \\
\text { Demands }\end{array}$ \\
\hline $\begin{array}{l}\text { Fairchild, R., } \\
\text { Brake J.F., }\end{array}$ & 2009 & $\begin{array}{l}\text { Using on-board driver feedback systems to } \\
\text { encourage safe, ecological and efficient }\end{array}$ & $\begin{array}{l}\text { Conference paper The } 23 \mathrm{rd} \\
\text { Convention of the Society for the Study }\end{array}$ & Driving Style \\
\hline
\end{tabular}




\begin{tabular}{|c|c|c|c|c|}
\hline $\begin{array}{l}\text { Thorpe N., } \\
\text { Birrell S.A, } \\
\text { Young, M.S., } \\
\text { Felstead T. \& } \\
\text { Fowkes M. }\end{array}$ & & driving: the foot-lite project. & $\begin{array}{l}\text { of Artificial Intelligence and } \\
\text { Simulation of Behaviour. Edinburgh. }\end{array}$ & \\
\hline Fuller, R. & 2005 & Towards a general theory of driver behaviour & $\begin{array}{l}\text { Journal: Accident Analysis and } \\
\text { Prevention }\end{array}$ & Task Difficulty; Changing Goals. \\
\hline $\begin{array}{l}\text { Gollwitzer } \\
\text { P.M., Sheeran } \\
\text { P., Troetschel, } \\
\text { R. \& } \\
\text { Webb, T.L. }\end{array}$ & 2011 & $\begin{array}{l}\text { Self-regulation of priming effects on } \\
\text { behavior }\end{array}$ & Journal: Psychological Science & $\begin{array}{l}\text { Behavioural Regulation; Goal } \\
\text { Protection; Goal Intentions; Goal } \\
\text { Access }\end{array}$ \\
\hline $\begin{array}{l}\text { Horrey W. J. \& } \\
\text { Lesch M. F. }\end{array}$ & 2009 & $\begin{array}{l}\text { Driver-initiated distractions: examining } \\
\text { strategic adaptation for in-vehicle task } \\
\text { initiation. }\end{array}$ & $\begin{array}{l}\text { Journal: Accident Analysis and } \\
\text { Prevention }\end{array}$ & Behavioural Regulation \\
\hline $\begin{array}{l}\text { Horrey W. J. \& } \\
\text { Simons D. J. }\end{array}$ & 2007 & $\begin{array}{l}\text { Examining cognitive interference and } \\
\text { adaptive safety behaviours in tactical vehicle } \\
\text { control. }\end{array}$ & Journal: Ergonomics & $\begin{array}{l}\text { Adapt To Demands; Resource } \\
\text { Constraints }\end{array}$ \\
\hline $\begin{array}{l}\text { Kircher K., Fors } \\
\text { C. \& Ahlstrom } \\
\text { C. }\end{array}$ & 2014 & $\begin{array}{l}\text { Continuous versus intermittentant } \\
\text { presentation of visual eco-drive advice }\end{array}$ & $\begin{array}{l}\text { Journal: Transportation Research Part } \\
F\end{array}$ & $\begin{array}{l}\text { Adapt To Demands; Feedback; } \\
\text { Environment }\end{array}$ \\
\hline $\begin{array}{l}\text { Koustanai, A., } \\
\text { Boloix E., } \\
\text { Van Elslande P. } \\
\text { \& Bastien C. }\end{array}$ & 2008 & $\begin{array}{l}\text { Statistical analysis of "looked-but-failed-to- } \\
\text { see" accidents: highlighting the involvement } \\
\text { of two distinct mechanisms }\end{array}$ & $\begin{array}{l}\text { Journal: Accident Analysis and } \\
\text { Prevention }\end{array}$ & Environment; Perceptual Failure \\
\hline $\begin{array}{l}\text { Lee J. D., } \\
\text { Roberts S.C., } \\
\text { Hoffman J.D. \& } \\
\text { Angell L.S. }\end{array}$ & 2012 & $\begin{array}{l}\text { Scrolling and driving: how an mp3 player } \\
\text { and its aftermarket controller affect driving } \\
\text { performance and visual behavior }\end{array}$ & Journal: Human Factors & $\begin{array}{l}\text { Adaption To Demands; Task Length; } \\
\text { Resource Constraints }\end{array}$ \\
\hline $\begin{array}{l}\text { Metz B., } \\
\text { Schoemig N., \& } \\
\text { Krueger H.P. }\end{array}$ & 2011 & $\begin{array}{l}\text { Attention during visual secondary tasks in } \\
\text { driving: adaptation to the demands of the } \\
\text { driving task. }\end{array}$ & $\begin{array}{l}\text { Journal: Transportation Research Part } \\
\text { F-Traffic Psychology and Behaviour }\end{array}$ & Adapt To Demands; Task Difficulty \\
\hline $\begin{array}{l}\text { Monk C. A., } \\
\text { Boehm-Davis } \\
\text { D. A. \& } \\
\text { Trafton J. G. }\end{array}$ & 2004 & $\begin{array}{l}\text { Recovering from interruptions: implications } \\
\text { for driver distraction research. }\end{array}$ & Journal: Human Factors & Goal Access; Task Switching \\
\hline
\end{tabular}




\begin{tabular}{|c|c|c|c|c|}
\hline $\begin{array}{l}\text { Rakauskas, M. } \\
\text { E., Gugerty L. J. } \\
\text { \& } \\
\text { Ward N. J. }\end{array}$ & 2004 & $\begin{array}{l}\text { Effects of naturalistic cell phone } \\
\text { conversations on driving performance }\end{array}$ & Journal: Journal of Safety Research & Adapt To Demands; Effort \\
\hline $\begin{array}{l}\text { Ramirez M., } \\
\text { Yang J., } \\
\text { Young, T., } \\
\text { Roth L., } \\
\text { Garinger, A., } \\
\text { Snetselaar, L. \& } \\
\text { Peek-Asa, C. }\end{array}$ & 2013 & $\begin{array}{l}\text { Implementation evaluation of steering teens } \\
\text { safe: engaging parents to deliver a new } \\
\text { parent-based teen driving intervention to } \\
\text { their teens }\end{array}$ & Journal: Health Education \& Behavior & Changing Goals \\
\hline $\begin{array}{l}\text { Robert G. \& } \\
\text { Hockey J. }\end{array}$ & 1997 & $\begin{array}{l}\text { Compensatory control in the regulation of } \\
\text { human performance under stress and high } \\
\text { workload: a cognitive-energetical framework }\end{array}$ & Journal: Biological psychology & $\begin{array}{l}\text { Adapt To Demands; Goal Conflict; } \\
\text { Goal Priority; Behavioural Regulation; } \\
\text { Effort; Motivation; Goal Protection; } \\
\text { Environment }\end{array}$ \\
\hline $\begin{array}{l}\text { Roca J., Castro } \\
\text { C., } \\
\text { Bueno M. \& } \\
\text { Moreno-Rios S. }\end{array}$ & 2012 & $\begin{array}{l}\text { A driving-emulation task to study the } \\
\text { integration of goals with obligatory and } \\
\text { prohibitory traffic signs }\end{array}$ & Journal: Applied Ergonomics & $\begin{array}{l}\text { Goal Conflict; Task Difficulty; Goal } \\
\text { Congruency }\end{array}$ \\
\hline $\begin{array}{l}\text { Ross V., Jongen } \\
\text { E.M.M., } \\
\text { Wang W., } \\
\text { Brijs T., } \\
\text { Brijs K., } \\
\text { Ruiter R.A.C. \& } \\
\text { Wets G. }\end{array}$ & 2014 & $\begin{array}{l}\text { Investigating the influence of working } \\
\text { memory capacity when driving behavior is } \\
\text { combined with cognitive load: an lct study of } \\
\text { young novice drivers }\end{array}$ & $\begin{array}{l}\text { Journal: Accident Analysis and } \\
\text { Prevention }\end{array}$ & $\begin{array}{l}\text { Goal Rehearsal; Working Memory } \\
\text { Capacity }\end{array}$ \\
\hline $\begin{array}{l}\text { Salvucci, D. D. } \\
\& \text { Taatgen N. A. }\end{array}$ & 2008 & $\begin{array}{l}\text { Threaded cognition: an integrated theory of } \\
\text { concurrent multitasking }\end{array}$ & Journal: Psychological review & $\begin{array}{l}\text { Adapt To Demands; Goal Conflict; } \\
\text { Resource Constraints; Task Switching }\end{array}$ \\
\hline $\begin{array}{l}\text { Schmidt-Daffy } \\
\text { M., } \\
\text { Brandenburg, S. } \\
\& \\
\text { Beliavski A. }\end{array}$ & 2013 & $\begin{array}{l}\text { Velocity, safety, or both? How do balance } \\
\text { and strength of goal conflicts affect drivers' a, } \\
\text { feelings and physiological responses? }\end{array}$ & $\begin{array}{l}\text { Journal: Accident Analysis and } \\
\text { Prevention }\end{array}$ & $\begin{array}{l}\text { Behavioural Regulation; } \\
\text { Goal Conflict } \\
\text { Goal Priority; Goal Strength. }\end{array}$ \\
\hline Sheridan T.B. & 2004 & $\begin{array}{l}\text { Driver distraction from a control theory } \\
\text { perspective }\end{array}$ & Journal: Human Factors & Goal Intention; Effort. \\
\hline Tanida K. & 2010 & $\begin{array}{l}\text { New description for driving behavior by tp- } \\
\text { theory based on cognitive psychology. }\end{array}$ & $\begin{array}{l}\text { Book Series: Cognitive Psychology } \\
\text { Perspectives }\end{array}$ & Goal Hierarchy; Anticipatory Control \\
\hline
\end{tabular}




\begin{tabular}{|l|l|l|l|l|}
\hline $\begin{array}{l}\text { Tanida K. \& } \\
\text { Poeppel E. }\end{array}$ & 2010 & $\begin{array}{l}\text { Tp-theory as new perspective on cognitive } \\
\text { psychology. }\end{array}$ & $\begin{array}{l}\text { Book Series: Cognitive Psychology } \\
\text { Perspectives }\end{array}$ & Goal Hierarchy; Anticipatory Control \\
\hline $\begin{array}{l}\text { Tanida K. \& } \\
\text { Poppel E. }\end{array}$ & 2006 & $\begin{array}{l}\text { A hierarchical model of operational } \\
\text { anticipation windows in driving an } \\
\text { automobile }\end{array}$ & Journal: Cognitive processing & Anticipatory Control \\
\hline $\begin{array}{l}\text { Tractinsky N., } \\
\text { Ram E.S \& } \\
\text { Shinar D. }\end{array}$ & 2013 & $\begin{array}{l}\text { To call or not to call-that is the question } \\
\text { (while driving). }\end{array}$ & $\begin{array}{l}\text { Journal: Accident Analysis and } \\
\text { Prevention }\end{array}$ & $\begin{array}{l}\text { Adapt To Demands; Behavioural } \\
\text { Regulation. }\end{array}$ \\
\hline $\begin{array}{l}\text { Verberne } \\
\text { F.M.F., Ham J. } \\
\text { \& } \\
\text { Midden C.J.H. }\end{array}$ & 2012 & $\begin{array}{l}\text { Trust in smart systems: sharing driving goals } \\
\text { and giving information to increase } \\
\text { trustworthiness and acceptability of smart } \\
\text { systems in cars }\end{array}$ & Journal: Human Factors & $\begin{array}{l}\text { Information Presentation; } \\
\text { Goal Congruency }\end{array}$ \\
\hline $\begin{array}{l}\text { Young M. S., } \\
\text { Birrell S.A. \& } \\
\text { Stanton, N.A. }\end{array}$ & 2011 & $\begin{array}{l}\text { Safe driving in a green world: a review of } \\
\text { driver performance benchmarks and } \\
\text { technologies to support 'smart' driving. }\end{array}$ & Journal: Applied Ergonomics & $\begin{array}{l}\text { Adapt To Demands; Goal Conflict; } \\
\text { Goal Priority; Goal Congruency; } \\
\text { Feedback; } \\
\text { Information Presentation; Driving } \\
\text { Style; Environment. }\end{array}$ \\
\hline $\begin{array}{l}\text { Young K. L., \& } \\
\text { Lenné M. G. }\end{array}$ & 2010 & $\begin{array}{l}\text { Driver engagement in distracting activities } \\
\text { and the strategies used to minimise risk. }\end{array}$ & Journal: Safety Science & $\begin{array}{l}\text { Adapt To Demands; Behavioural } \\
\text { Regulation; Motivation }\end{array}$ \\
\hline
\end{tabular}

